\title{
A study of the wound environment during total hip arthroplasty
}

\author{
J. McLauchlan \\ M.B., F.R.C.S. \\ J. R. C. LOGIE \\ M.B., F.R.C.S. \\ H. G. SMYLIE \\ G. SMITH \\ M.D., F.R.C.Path. \\ M.D., D.Sc., F.R.C.S., F.A.C.S. \\ Departments of Orthopaedics, Surgery, and Bacteriology, Aberdeen Royal Infirmary, Aberdeen
}

\begin{abstract}
Summary
Two hundred and seventeen total hip replacements were performed during a trial designed to assess the influence of a surgical isolator upon postoperative wound infection. The trial was controlled by performing 108 of the replacements in a standard plenumventilated theatre with twenty air changes/hr, which also housed the isolator procedures. Comparative postoperative wound infection rates were $6.4 \%$ for the isolator patients and $4.6 \%$ for those operated on in the plenum-ventilated theatre. There was intraoperative wound contamination in both groups of patients and, although the isolator reduced wound contamination at operation, this bore no relationship to eventual wound sepsis.
\end{abstract}

\section{Introduction}

Published reports of major postoperative wound infection rates for total hip arthroplasty vary from $0.1 \%$ to $10 \%$. The multi-factorial nature of such infection is emphasized by a variety of reports ranging from the influence of joint cement, prosthetic materials, prophylactic antibiotic therapy to both direct contact and airborne cross-infection. The advent of the surgical isolator (McLauchlan et al., 1974) based on the plastic flexible film isolator (Trexler and Reynolds, 1957) provided an opportunity to evaluate some of these factors. The isolator, unlike any other ultra-clean air system, effectively blocks both the airborne and direct contact routes of cross-infection during operation. The effects of ultra-clean air conditions using the isolator have already been described (McLauchlan et al., 1976). The following sets out the whole trial in more detail.

\section{Methods}

A controlled trial was set up using the isolator (Fig. 1) in a standard plenum ventilated theatre. Patients were randomly allocated to have their hip replacements with or without the isolator. Two patients were operated on each morning. The same procedure was employed by the same surgeon
(J.M.) throughout the trial. The patients were nursed and had their wounds dressed in an open Nightingale-type ward. No prophylactic antibiotics were used. Samples for bacteriological study were collected as set out in Table 1 .

\section{Classification of postoperative wound sepsis}

The clinical examination of all wounds by the same observers (J.M. and J.R.C.L.) was correlated with the results of the bacteriological studies. The classification previously used (Davidson et al., 1971) was followed.

\section{Clean wounds}

No clinical or bacteriological evidence of infection.

\section{Infected wounds}

(a) Major-those requiring further active treatment with antibiotics, wound exploration or irrigation, or removal of the prosthesis.

(b) Minor-those showing limited redness or discharge in relation to the suture line with evidence of pus and bacteria from wound swabs, but the wound healing without active therapy.

(c) Primary or secondary-both major and minor infections were sub-grouped 'primary' or 'secondary' when monitoring exposed an aetiological relationship to theatre or ward environments respectively.

\section{Results}

\section{The patients}

A total of 222 patients requiring total hip replacement were admitted to the trial. A fatal pulmonary embolus, fracture at operation, exposure of pus around an old Zimmer nail plate and on two occasions monitoring failure, resulted in the withdrawal of five patients. Of the remaining 217, 109 were operated on in the surgical isolator and 108 served as plenum theatre controls. The groups were discovered to be very similar in terms of age, sex, preoperative diagnoses, previous surgical procedure, operative time and postoperative wound drainage 


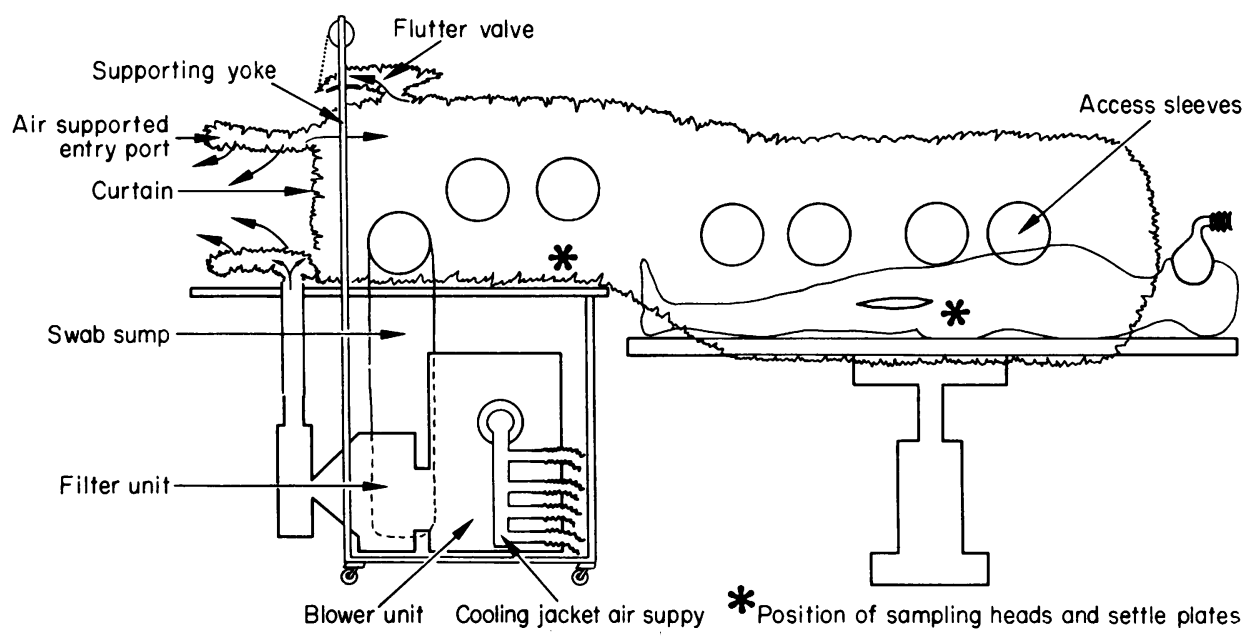

FIG. 1. Diagram of the surgical isolator fully inflated and in position on hip. Only the incised wound is exposed to the sterile interior of the isolator, the rest of the patient and all operators and assistants being external to the wound environment. Note the position of air sampling devices inside the isolator.

TABLE 1

Patient
On admission
At operation

Blood cultures

Drainage fluid

Final bacteriological assessment of wound

Theatre

Nasal swabbing

Glove and finger

Air hygiene studies
Swabs from nose, throat, and perineum.

Skin over operation site before and after disinfection.

Skin edges after incision and before closure including biopsies.

All layers of wound down to and back up from bone.

All instruments in close and repeated contact with wound and scalpel blades.

Joint cement, aerosol adhesives, adhesive drapes.

At start of operation, 30 and $60 \mathrm{~min}$ later then 4 and $24 \mathrm{hr}$ postoperatively.

At closure and on removal of drain at $48 \mathrm{hr}$.

At dressing 14 days postoperatively unless soakage of dressings by wound drainage fluid or pyrexia previously.

Of all personnel weekly.

Streak plating at end of operation.

Inside isolator and in plenum-ventilated theatre by slit-samplers and $9 \mathrm{~cm}$ diameter settle plates.
(Table 2). Nor was there any major difference in bacteriological status on admission-there being nasal carriage rates for Staphylococcus pyogenes of $27 \%$ and $20.3 \%$ in isolator and control groups respectively, and no significant throat carriage of Group A Streptococcus haemolyticus.

\section{The bacteriology of the operative procedure}

Wound contamination during operation. Staph. pyogenes was isolated from the hip skin of four patients before disinfection on the table. Postdisinfection sampling on inhibitor media proved the efficiency of $2.5 \%$ iodine in $70 \%$ ethyl alcohol, nearly all samples including those from skin carriers of Staph. pyogenes remaining sterile on incubation. Sampling of wound and instruments throughout the operative procedure revealed evidence of bacterial contamination of the wound in thirty-nine $(36 \%)$ isolator patients and sixty-three $(58 \%)$ plenum theatre patients. The bacteria were seen to be related to the linear impressions on the surface of bandageagar sampling plates formed by the wound edges. Major bacterial contamination of the wound (more than 100 colonies/operation) was observed in 
TABLE 2. Two hundred and seventeen total hip replacements

\begin{tabular}{lcc}
\hline & $\begin{array}{c}\text { Surgical } \\
\text { isolator }\end{array}$ & $\begin{array}{c}\text { Plenum } \\
\text { theatre }\end{array}$ \\
\hline Patients & 109 & 108 \\
Male & 45 & 54 \\
Female & 64 & 54 \\
Average age & 67 & 67 \\
Average operating time & $71 \mathrm{~min}$ & $72 \mathrm{~min}$ \\
Average wound drainage & $556 \mathrm{ml}$ & $575 \mathrm{ml}$ \\
Pre-operative diagnosis & & \\
Osteoarthritis & 98 & 95 \\
Rheumatoid arthritis & 6 & 6 \\
Avascular necrosis & 4 & 6 \\
Steroid arthritis & 1 & 1 \\
Traumatic dislocation & - & 11 \\
Previous operation & & 2 \\
Osteotomies & 10 & 3 \\
Sliding nail plates & 1 & 2 \\
Smith-Petersen nails & 2 & 1 \\
Removal of nails & 3 & - \\
Bohlmans pins & 1 & \\
Psoas tenotomies & 2 & \\
Bone graft & 1 & \\
& &
\end{tabular}

twelve and eleven of isolator and plenum theatre operations respectively. In these patients, wounds were discovered to be contaminated at an early stage of the operation. They became more heavily contaminated as the operation proceeded. Sometimes by the end of the procedure both wound edge biopsies and the surgeon's knife yielded heavy growths on agar plates (Fig. 2). In seventeen of the heavily contaminated wounds the organisms were all coagulase negative staphylococci, pigmented or non? pigmented or, as was often the case, a mixture of both. Staph. pyogenes was isolated from the cultures. obtained from the remaining six patients (thre $\overrightarrow{\mathrm{E}}$ isolator and three control) of whom four were nasat carriers. In only one instance was the pathogen the dominant wound isolate. This patient revealed ne carriage of the pathogen in either nose, throat of perineum, and his wound, as in the case of the othe? five potentially highly infective contaminationss? healed cleanly.

Skin biopsies taken at the start of operation and laid on to blood agar yielded cultures in $3.1 \%$ of isolator cases and $7 \cdot 3 \%$ of control cases, while those taken at the end increased the percentage yield to $4.3 \%$ and $14.1 \%$ respectively. Agar impressions from the surface of the adhesive drape applied to the skin at the end of operation, yielded cultures op organisms from $19 \cdot 6 \%$ of isolator cases and $29 \cdot 2 \%$ of the control cases. Analysis of blood cultures revealed no instance of bacteraemia in any of the patients. Cultures of joint cement and aerosot adhesive revealed no evidence of wound contamina $\overrightarrow{\bar{c}}$ tion from these sources. Bacterial contamination o $\$$ the surgeon's knife was found in relation to eight of the twenty-three heavier wound contaminatiens detected during the trial.

\section{Wound infection}

The comparative postoperative wound infecton rates for the two groups of patients were $6.4 \%$ (seveng and $4.6 \%$ (five) for isolator and control series respectively, with only two major wound infections $(1.8 \%)$ in each group (Table 3 ).

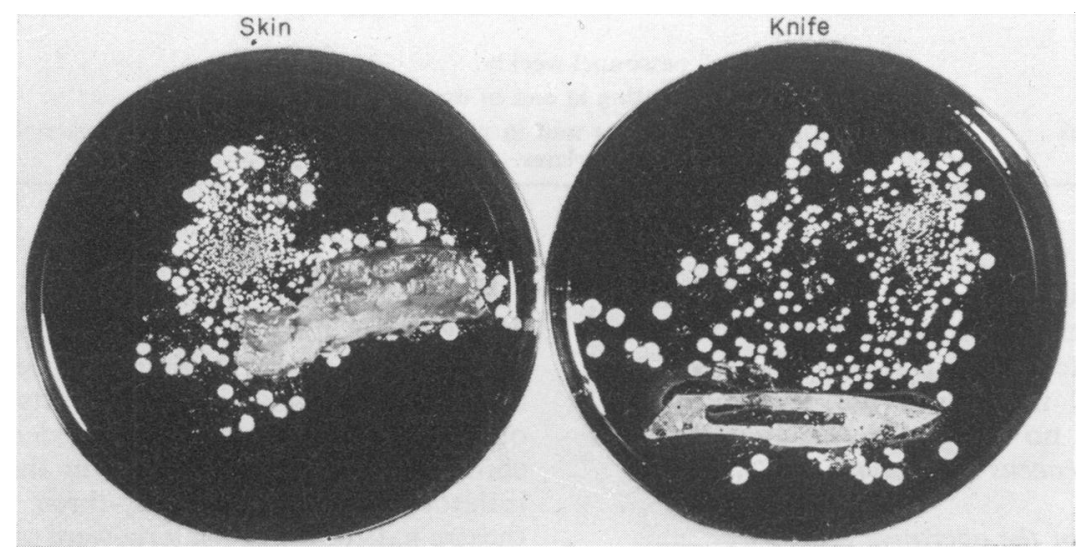

FIG. 2. Heavy bacterial contamination of both the wound edge biopsy taken immediately before wound closure, and the surgeon's knife-from Op. No. 190, an isolator procedure, and one of the twenty-four patients revealing heavy intra-operative wound contamination during the trial. 
TABLE 3. Classification of postoperative wound sepsis occurring in 217 total hip arthroplasties according to their operative environment

\begin{tabular}{|c|c|c|c|c|c|}
\hline \multirow[b]{2}{*}{ No. of patients } & \multirow[b]{2}{*}{ Operative environment } & \multicolumn{2}{|c|}{ Major infections } & \multicolumn{2}{|c|}{ Minor infections } \\
\hline & & Primary & Secondary & Primary & Secondary \\
\hline $\begin{array}{l}109 \\
108\end{array}$ & $\begin{array}{l}\text { Surgical isolator } \\
\text { Plenum ventilated theatre }\end{array}$ & $\begin{array}{l}\mathbf{0} \\
\mathbf{0}\end{array}$ & $\begin{array}{l}2(1.8 \%) \\
2(1.8 \%)\end{array}$ & $\begin{array}{l}\mathbf{0} \\
\mathbf{0}\end{array}$ & $\begin{array}{l}5(4 \cdot 5 \%) \\
3(2 \cdot 7 \%)\end{array}$ \\
\hline
\end{tabular}

Major infections. In all four instances where major wound infection developed there was soakage of dressings by wound drainage fluid so that they had to be changed within the first or second postoperative day. All were due to faulty wound drainage. In three, wound haematomas occurred. Initially the wound discharges appeared sterile, but became infected at the end of the first postoperative week. Swabs then yielded a mixed growth involving various combinations of Escherichia coli, Proteus sp., Strep. faecalis, Pseudomonas aeruginosa and diphtheroid bacilli. Still later, in one instance after a delay of 3 weeks from the start of proved mixed wound infection, Staph. pyogenes could also be isolated from these mixed growths. There was no strain similarity between these late isolates of Staph. pyogenes. Two were untypable but of differing antibiotic sensitivity pattern, and the other two strains were typed 42E/and $29 / 62 / 77 /-$. The latter was present in the anterior nares of the affected patient. Two of the four major infections, one an isolator and the other a control procedure showed no operative wound contamination. In the other two, again one isolator and one non-isolator case, Staph. epidermidis was a heavy contaminant of the former wound and a light contaminant of the latter. In neither instance was this species isolated from the infective wound discharge.

Minor infection. Of the eight cases of minor wound infection only one was not a mixed infection. In this isolator patient the wound swab at the fourteenth postoperative day yielded only debris and aerobic spore-bearing bacilli. On the twentieth postoperative day repeat swabbing revealed pus and a growth of a penicillin-insensitive phage type $85 /-$ Staph. pyogenes. The patient was not a carrier of this strain. The time taken to develop infection plus the absence of this strain among theatre isolates was highly suggestive of a ward rather than a theatre source. $E$. coli appeared as the dominant growth in the other mixed infections except in one patient when this was $P$. aeruginosa. Accompanying species were either Proteus, aerobic spore-bearing bacilli, Strep. faecalis, diphtheroid bacilli or, in one instance, Clostridium welchii. Only three of the minor infections (one isolator and two control procedures) suffered demonstrable wound contamination in theatre. Staph. epidermidis was a light contaminant in the isolator and one of the control procedures, and a heavy contaminant in the other control case. Staph. epidermidis was not isolated from the infective wound discharges of these three patients.

\section{The bacteriology of the operative environment}

Air hygiene studies. Because every procedure was monitored by membrane sampler and settle plate it was possible to demonstrate the marked differences in standards of air hygiene between the two groups and also the regularity and steadiness of these standards within each group.

Bacterial counts. (1) The surgical isolator. So as to exclude the possibility of a dead space pattern of isolator ventilation two well spaced membrane sampling heads were used, one at the top end of the wound, the other at the instrument table. With each, a settle plate was placed. By this method, $5,321 \mathrm{cu} . \mathrm{ft}$ of isolator air were sampled in conjunction with $196 \mathrm{hr}$ of settle plate exposure. The sampling periods employed ranged from 5 to $60 \mathrm{~min}$. This resulted in the isolation of only two colonies by membrane sampling and six by sedimentation on the settle plates, a result well within the acceptable level of accidental handling contamination and proof of the constant sterility of the aerial environment. At intervals further checks on the validity of this result were carried out using a 'Casella Slit Sampler' for $1 \mathrm{~min}$, 2 min and 5 min sampling periods. All plates exposed in this way to isolator air remained sterile.

(2) The Plenum theatre. Membrane sampling. During the control series of hip replacements performed in the plenum theatre, membrane sampling times were restricted ranging from 5 to a maximum of $30 \mathrm{~min}$ in order to cope with the expected concentrations of airborne bacteria. A total of $2,995 \mathrm{cu}$. $\mathrm{ft}$ of air was sampled demonstrating a mean average concentration of airborne bacteria-carrying particles of $6 \cdot 2 / \mathrm{cu}$. $\mathrm{ft}$. There was no significant difference in the concentrations measured at the wound as opposed to the instrument table.

Settle plates. (a) Theatre. These were placed at opposite sides of the theatre for all 217 operations. They revealed a mean average sedimentation rate of 28.5 bacteria-carrying particles/plate/hr at one 
side of the theatre and $14 \cdot 2$ at the other. The difference was expected since most of the movement of personnel and supplies took place at the side of the theatre showing the heavier rate of settle. There was no significant difference in sedimentation rates as between isolator and control series of operations.

(b) Operating table. The wound and instrument table settle plates, approximately equidistant and central to those at the sides of the theatre, revealed sedimentation rates of 19.4 and $19.8 / \mathrm{hr}$ respectively, approximately $4 \cdot 7$ particles $/ \mathrm{sq}$. $\mathrm{ft} / \mathrm{min}$. As the settle rate of such particles (average size $10-15 \mu \mathrm{m}$ ) is such that the number settling per sq. $\mathrm{ft}$ per min is approximately equal to the number contained in $1 \mathrm{cu}$. $\mathrm{ft}$ of air, the rates observed would suggest the presence of four or five such particles per cu. $\mathrm{ft}$ of air at the wound. Apart from occasional aerobic spore-bearers and fungi, colonies grown were almost entirely saprophytic cocci, Staph. pyogenes being isolated (usually a single colony) during only eight of the control procedures. With a wound surface area of roughly $1 / 3$ of a sq. $\mathrm{ft}$ approximately ninety such particles might be expected to reach the exposed tissues during operations. Despite this assumption nearly half the wounds made in the plenum ventilated theatre revealed no detectable bacterial contamination while a similar proportion of wounds exposed in the sterile aerial environment of the surgical isolator did. It appears, therefore, that wound contamination in both groups of patients was largely due to the release of resident skin flora from wound edges and not to bacterial 'fall-out' from theatre air, although this latter factor may have had a small part to play in the marginally higher contamination rates observed in the control series of patients.

Total particle counts. These were performed in both the surgical isolator and the plenum theatre by the Royco particle sampler with five channel digital read-out on the size range of $0.5 \mu \mathrm{m}, 1.0 \mu \mathrm{m}, 5 \mu \mathrm{m}$, $10 \mu \mathrm{m}$, and $15 \mu \mathrm{m}$ on twelve separate occasions. The results summarized in Table 4 along with bacteriacarrying particle counts from membrane sampling reveal bacterial contamination to be an infinitesimal part of the total particle content of the air in the plenum theatre and that when swabs were taken, bone sawn, and cement powder mixed, counts were as high and in some size ranges higher inside the surgical isolator.

\section{The operating team}

Of the regular members of the operating team $38.2 \%$ were nasal carriers of Staph. pyogenes. Throughout the trial period the surgeon and two of his assistants were heavy nasal carriers of strains exhibiting the usual hospital pattern of multiple antibiotic resistance, the former carrying a phage type $29 / 52 / 80 /$ while the latter both carried a strain typed by nearly all of the phage Group III lysates.

\section{Contamination of the operators' hands}

From previous experience (Smylie, Webster and Bruce, 1959; Smylie, Logie and Smith, 1973) it was considered important to assess the bacteriological state of the outside of surgical gloves after wound closure and before removal. Plate-streak sampling was therefore carried out on members of the team firstly on their gloved hands as a test of intra-operative contamination and again after glove removal to assess residual disinfection of skin. Figure 3 demonstrates a typical result of such sampling. Both the inner and outer pairs of surgeon's gloves were punctured in $21.2 \%$ of operations but in only $2.4 \%$ of operations was this double puncture associated with a positive culture from the skin of the surgeon's hands, and in no instance were such organisms detected on the external glove surface. Bacteriological monitoring of the outside of the gloves and of the patient's skin was completed in ninety-five isolator and ninety-eight plenum theatre operations. This showed that contamination of the outside surface of the surgeon's glove at wound closure occurred in eighteen and thirty-four of these procedures respectively. Taking the surgeon's glove as the most relevant wound handling risk, and classifying wounds into those which remained clean throughout and those showing either light $(<10$ colonies isolated from the wound/operation), moderate $(>10,<100)$ and heavy contamination $(>100)$, it was seen that although sometimes the surgeon's gloves were found to be dirty when the wound was apparently clean and vice versa, in general his glove contamination increased in direct proportion to the degree of wound contamination (Fig. 4). Contamination of the surgeon's gloves was invariably accompanied by similar contamination of the gloves of one or more of his assistants. All such contaminants were morphologically identical to those found in the wounds handled.

\section{Discussion}

Although postoperative wound infection is recognized as multi-factorial in origin, argument continues on the relative importance of the sources of such infection in the total environment of the surgical patient. Since Lister, surgeons have concentrated upon control of the theatre environment as the best means of reducing infection in the wounds they create. Consequently, the architecture of the operating theatre has passed through many stages reaching the ultimate in ultra-clean environmental control systems such as the surgical isolator (McLauchlan et al., 1974; Trexler and Reynolds, 1957) and the laminar flow-ventilated operating enclosure 


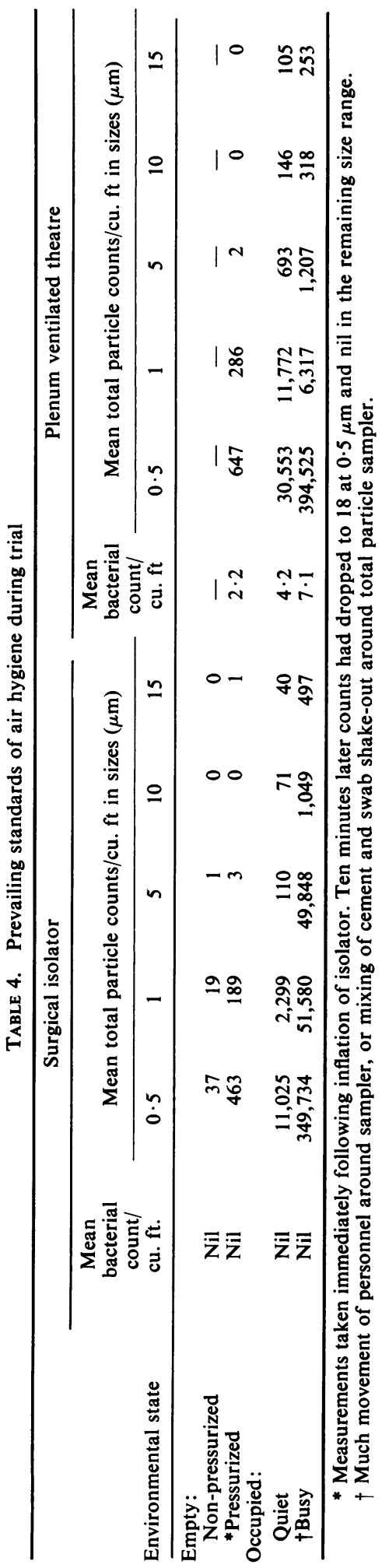




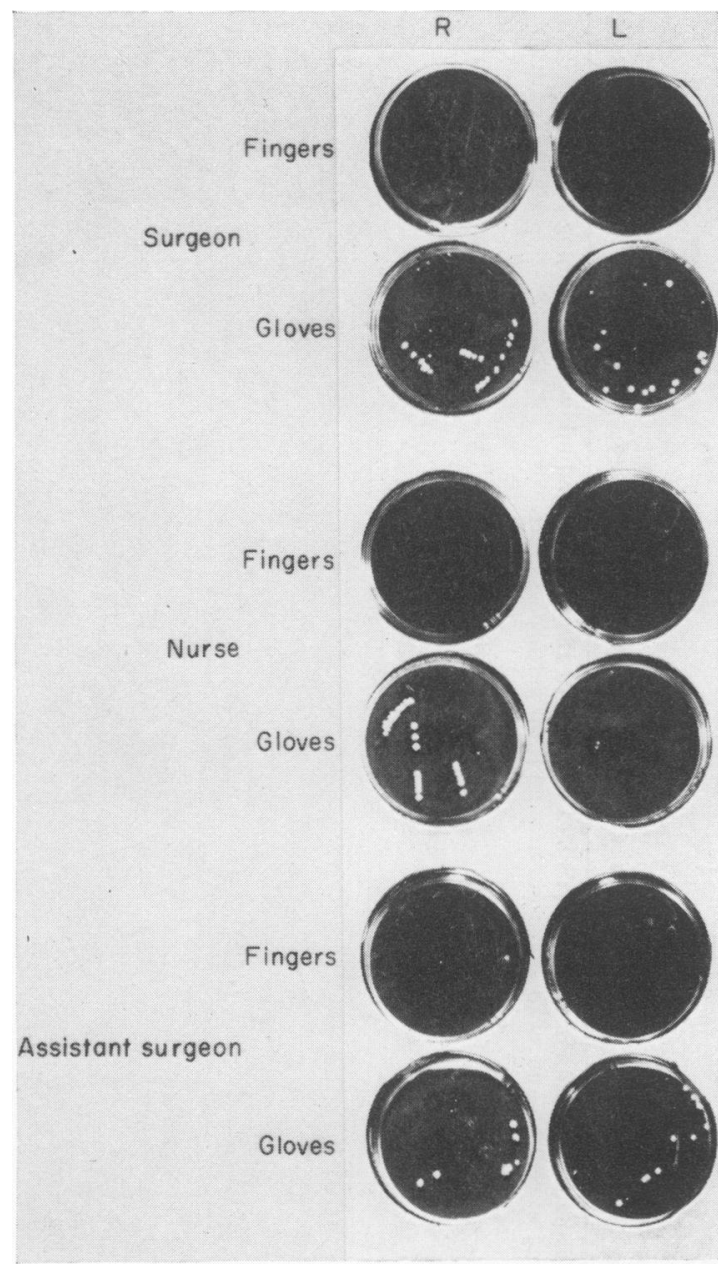

FIG. 3. Intra-operative wound contamination resulting in bacterial contamination of the external surface of the gloves of the operating team while skin of hands inside gloves remains clean. Postoperative plate streaks (case 190).

(Charnley, 1964). Moreover, progress in the control of direct contact cross-infection in theatre is now so sophisticated, that throughout even the longest operation bacterial recontamination of the skin of the operating hand inside its protective rubber glove can be largely abolished, thus reducing the bacteriological consequences of glove puncture to negligible proportions. All kinds of sterile supplies for the operative procedure are now guaranteed in most modern theatres via quality controlled Central Sterile Supply Departments, Theatre Sterile Supply Units and commercial suppliers all using the most advanced and efficient of modern sterilizing equipment. In marked contrast, scant attention has been

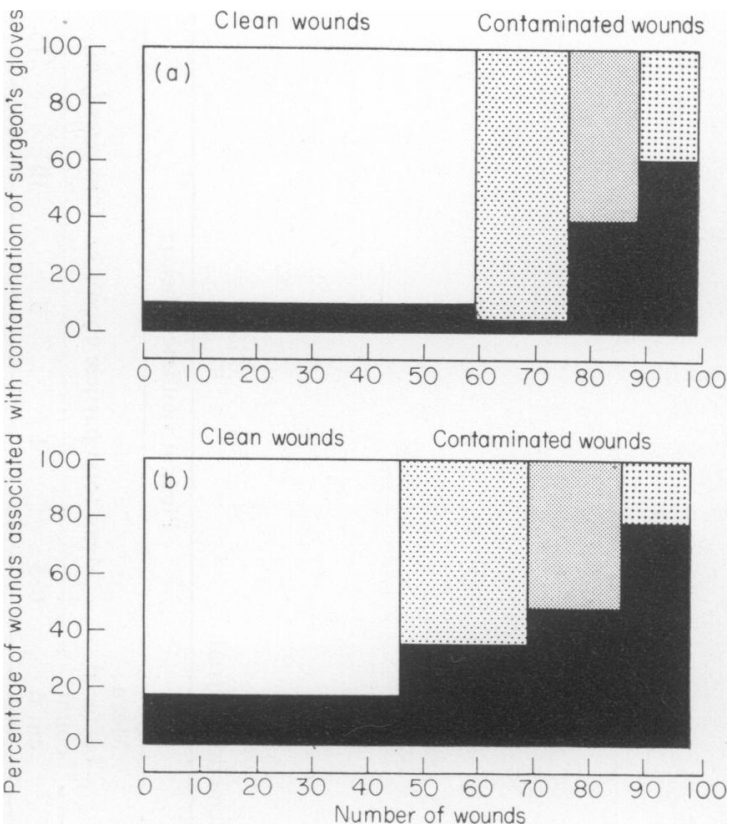

FIG. 4. The relationship between bacterial contamination of wounds and the surgeon's gloves during operations in the surgical isolator (a) and plenum ventilated theatre (b). The number of clean wounds and lightly, moderately or heavily contaminated wounds (see text) in each type of operating environment is demonstrated and the percentage of them associated with bacterial contamination of the operative surface of the surgeon's gloves. $\square$, clean; $\square$, light; fine screen, moderate; : $:$ heavy; $\square$, contamination of surgeon's gloves.

paid to the ward environment. Therefore it was with great interest that we embarked on a trial of the surgical isolator for total hip replacement in patients nursed in multi-bedded wards.

The surgical isolator provided precise control of the sterile environment eliminating the airborne and direct-contact cross-infection hazards. In clean operations such as total hip arthroplasty the sources of wound contamination and their relationship to postoperative infection are not clear. One publication (Charnley and Eftekhar, 1969) assesses wound contamination at operation from airborne bacteria as of extreme importance in the aetiology of postoperative sepsis and attributes a drop in wound infection over 7 years to the use of an operating enclosure supplied with 300 air changes/hr and special exhaust-ventilated theatre clothing. Unfortunately, insufficient bacteriological monitoring in such studies still leaves considerable doubt as to the exact role of clean air.

Air sampling checks proved the sterility of the aerial environment of the surgical isolator. By contrast, the air of the plenum ventilated theatre used 
for the control series of operations contained an average of 6.2 bacteria-carrying particles/cu.ft during procedures with a settle rate at the wound of between 4 and 5 particles/sq. $\mathrm{ft}$ per min. It therefore closely approximates the reviewed standard for efficient plenum ventilation of operating rooms (Blowers, 1962). Despite this difference in the aerial environments of the two operation systems wound contamination during operation was apparent in both 'isolator' and 'plenum theatre' patients. The levels of such bacterial contamination were frequently far in excess of any possible contribution from airborne bacteria. The frequency of contamination of the operative surface of the surgeon's gloves was in direct proportion to the degree of wound contamination, the bacterial species involved being exactly similar to those isolated from the wounds. In the absence of any proved bacterial leakage from the surgeon's glove, the only demonstrable source of these organisms, predominantly Staph. epidermidis, was the patient's skin. There was no aetiological relationship between wound contamination and recorded cases of postoperative wound sepsis and, to date, in a follow-up period of between 12 and 24 months, no patient has developed late infection. The aetiology of the major infections, two in each group, was related to heavy and immediate wound soakage and faulty drainage with the associated opportunities for bacterial invasion of the wound. Repeated sampling showed these discharges to be sterile initially, only yielding positive cultures after 7-10 days, predominantly of a mixed faecal type flora such as is commonly isolated from both the bedclothes and the perineal region of patients. Of the eight minor infections only one did not show a similar mixed infection. The exception developed infection on the twentieth postoperative day from a strain of Staph. pyogenes undetected during theatre monitoring. Consequently, all infections, whether major or minor, were classed as secondary, reflecting an aetiology which was properly related to the opportunities for infection in the ward rather than in the theatre.

In this trial we have shown that operating in a sterile environment reduces wound contamination at operation. It could be argued that a valid statistical result would require a longer series of observations, but so far there appears to be no aetiological relationship between operative wound contamination and subsequent wound infection. Those patients whose wounds were heavily contaminated with Staph. epidermidis may be at risk to late infection. This organism is well documented as a cause of infection following heart surgery (Hoffman et al., 1959). Whether or not infection occurs may be related to the type of micrococcus involved as shown by Selwyn and Ellis (1972).

\section{Acknowledgments}

We would like to thank our orthopaedic colleagues for their co-operation and the nursing staff of Stracathro Hospital without whom this study would have been impossible. The work was supported by a generous grant from the Advisory Committee for Medical Research.

\section{References}

BLOWERS, R. (1962) Council for International Organisation of Medical Sciences-Infections in Hospitals Symposium, 199.

Charnley, J. (1964) A clean-air operating enclosure. British Journal of Surgery, 51, 202.

Charnley, J. \& Eftekhar, N. (1969) Post-operative infection in total arthroplasty of the hip with special reference to the bacterial content of the air. British Journal of Surgery, 56, 641.

Davidson, A.I.G., Smylie, H.G., Macdonald, A. \& Smith, G. (1971) Ward design in relation to post-operative wound infection II. British Medical Journal, 1, 72.

Hoffman, F.G., Zimmerman, S.L., Bradley, E.A. \& LAPIDUS, B. (1959) Bacterial endocarditis after surgery for acquired heart disease. Report of two cases and review of the literature. New England Journal of Medicine, 260, 152.

Mclauchlan, J., Logie, J.R.C., Smylie, H.G. \& Smith, G. (1976) The role of clean air in wound infection acquired during operation. Surgery, Gynecology and Obstetrics, 143, 6.

Mclauchlan, J., Pilcher, M.F., Trexler, P.C. \& Whalley, R.C. (1974) The surgical isolator. British Medical Journal, $1,322$.

SelwyN, S. \& Ellis, H. (1972) Skin bacteria and skin disinfection reconsidered. British Medical Journal, 1, 136.

Smylie, H.G., Logie, J.R.C. \& Smith, G. (1973) From Phisohex to Hibiscrub. British Medical Journal, 4, 586.

Smylie, H.G., Webster, C.V. \& BRuce, M.L. (1959) Phisohex and safer surgery. British Medical Journal, 2, 606.

Trexler, P.C. \& Reynolds, L.T. (1957) Flexible film apparatus for rearing and the use of germfree animals. Applied Microbiology, 5, 406. 